\title{
A Cohort Study Using Preoperative IL-6/Stat3/IL-17 And Blood Aminotransferase Levels To Predict Five-Year Survival For Patients After Liver Cancer Resection
}

Lijie Wang (D641302483@qq.com)

Shihezi University https://orcid.org/0000-0003-4914-9781

Xiaoning Li

Shihezi University School of Medicine

Lin Tao

Shihezi University School of Medicine

Wenjie Zhang

Shihezi University School of Medicine

\section{Research Article}

Keywords: HCC, Liver cancer, IL-6, Stat3, IL-17, Survival prognosis, Aminotransferases

Posted Date: March 9th, 2021

DOI: https://doi.org/10.21203/rs.3.rs-261872/v1

License: @ (i) This work is licensed under a Creative Commons Attribution 4.0 International License. Read Full License 


\section{Abstract}

Objective: The expression/activation of p-Stat3, IL-6 and IL-17 in hepatocellular carcinoma (HCC) tissues together with the serum levels of aminotransferases ALT, AST, GGT and ALP were designed to evaluate their abilities in predicting the survival prognosis of postoperative patients with HCC.

Methods: The clinicopathological data and paraffin-embedded tissues of 98 patients who underwent liver tumor resection were collected at the First Affiliated Hospital of Shihezi University School of Medicine, and the patients were followed-up after surgery. Immunohistochemistry (IHC) was used to detect the activation/expression of p-Stat3, IL-6 and IL-17 using tissue microarrays derived from these patients. Before surgery, patients' serum levels of AST, ALT, GGT and ALP were measured using a Roche Modular DPP automated biochemical analyzer. Statistical analyses were performed using non-parametric tests, Spearman's correlation, ROC curves, Kaplan-Meier survival analysis, Cox single-factor and multifactor regression models.

Results: (1) The strong positive rate of expressed IL-6 in HCC tissues (18.09\%) was lower than that in paracancerous tissues $(60.06 \%)(p<0.001)$; the strong positive rate of expressed IL-17 in HCC tissues (42.40\%) was lower than that in paracancerous tissues $(87.80 \%)(p<0.001)$. The strong positive rate of activated $p$-Stat3 in HCC tissues $(52.20 \%)$ was higher than paracancerous tissues (18.04\%) ( $p=0.01)$. (2) The higher the levels of ALT ( $p<0.001)$, AST $(p=0.002)$, GGT ( $<<0.001)$, and ALP $(p<0.001)$ were, respectively, the worse the survival prognoses were observed among HCC patients. (3) High levels of ALP were an independent risk factor for postoperative prognosis in HCC patients. (4) The combination of ALT+AST+ ALP appeared to be the best survival predictor for HCC patients as indicated by AUC $(0.820,95 \% \mathrm{Cl}=0.714,0.926)(p<0.001)$.

Conclusions: The activation/expression of p-Stat3, IL-6 and IL-17 differ in HCC tissues compared with their paracancerous tissues. Using classical TNM staging system as a reference, higher levels of serum aminotransferases ALT, AST, GGT and ALP are capable of predicting poor prognosis among postoperative HCC patients. ALT+AST+ALP+p-Stat3 is an optimal combination better than the classical TNM staging system in predicting postoperative survival among HCC patients. The observations presented may provide a useful guide for clinicians to strategize individualized surgical plans for liver cancer patients before surgery.

\section{Objective}

According to Global Cancer Statistics 2018, liver cancer (HCC) is one of the most common malignancies worldwide, with approximately 840,000 new cases and 780,000 deaths per year worldwide. In China, the incidence and the five-year survival rate of HCC are ranked third and fifth, respectively, among malignant tumors in China. ${ }^{1}$ Most liver cancers start insidiously and lack specific clinical manifestations. Although there has been advancement in relevant medical technologies, poor prognosis and high mortality rate of liver cancer have little changes due largely to unavailability of noninvasive prescreening methodologies.

Liver tissue biopsy is widely used for preoperative diagnosis of liver cancer and has a high diagnostic value, ${ }^{2}$ but the procedure's invasiveness has drawbacks. Postoperative pathological characteristics of HCC such as TNM clinical staging, degree of cell differentiation and depth of tumor infiltration, are indicative of patients' prognoses, but these indicators cannot be obtained preoperatively. Therefore, search for potential indicators that can be obtained preoperatively and show significant impacts on the survival prognosis of patients with liver cancer may provide useful guidance to surgeons in choosing optimal surgical approaches and postoperative treatment strategies to improve the quality of life as well as survival after surgery. This study has, therefore, investigated several potential bio-indicators that can be tested preoperatively and show impacts on patients' survival after surgery. These bio-indicators have included serum levels of several aminotransferases (ALT, AST, GGT, and ALP) and activational or expressed levels of the Stat3 signaling pathway (IL-6, p-Stat3 and IL-17) in tissues from patients with liver cancer. 


\section{Information And Methods}

\subsection{Subjects}

This study retrospectively collected 98 patients who underwent HCC resection at the First Affiliated Hospital, Shihezi University School of Medicine from January 2010 to December 2017, and the diagnoses of HCC were confirmed by two senior pathologists independently. All patients had complete demographic information and pathological data. This patient cohort included 74 males and 24 females with a mean age of 56.68 years and a median age of 57.0 years. None of the patients received adjuvant therapy such as radiotherapy or chemotherapy before surgery. Liver cancer tissues were non-necrotic tumor tissues and para-cancerous tissues were at least $2 \mathrm{~cm}$ away from the tumor edge.

\subsection{Detection of activation/expression of p-Stat3, IL-6, and IL-17 by immunohistochemistry (IHC)}

IHC method was performed in HCC and para-cancerous tissues using the Envision method. Briefly, paraffin chip sections were baked at $67^{\circ} \mathrm{C}$ for $30 \mathrm{~min}$, de-waxed and hydrated. After antigens were thermally repaired, $3 \% \mathrm{H}_{2} \mathrm{O}_{2}$ was added to block endogenous peroxidase activity and then, specific primary antibodies (against IL-6, IL-17 and p-Stat3 purchased from Abcam Co., USA) and secondary antibodies were added respectively, and color development was achieved using DAB.

\subsection{Scoring of Immunohistochemical stains}

Positive IHC stains were defined as yellow-brown color according to the manufacturer's demonstrative slides (Figure. 1). IHC staining slides were read on an Olympus optical microscope over yellow-brown color stains for 12 consecutive fields and scored according to two variable factors: (1) counting the number of positively stained cells $(0=<5 \% ; 1=6 \%-25 \% ; 2=$ $26 \%-50 \% ; 3=51 \%-75 \%$; and $4=76 \%-100 \%)$; and (2) scoring the intensity of the staining ( $0=$ absent; $1=$ Pale Brown-yellow; $2=$ Brown-yellow; 3 = Brown-yellow; 4 = Dark brown). The final score was the product of (1) multiplying (2) for individual slides (see Table S1). This scoring system was similar in principle to a published literature. ${ }^{3}$

\subsection{Serum aminotransferase measurements}

Upon admission to the hospital, venous blood $(3 \mathrm{ml})$ was collected from patients after fasting for 12 hours and levels of aminotransferases were measured using a Roche automatic biochemical analyzer. The aminotransferases tested were aspartate aminotransferase (AST), alanine aminotransferase (ALT), glutamyl transferase (GGT) and alkaline phosphatase (ALP).

\subsection{Patients' Follow-up}

Patients' follow-ups were achieved via telephone calls, outpatient interviews, and home visits. Follow-up was from October 2016 to October 2018, and patients were followed-up for 1-99 months after surgery.

\subsection{Diagnostic standard and reference value ranges}

The TNM staging was based on the eighth edition of TNM staging and cell differentiation of HCC was based on the latest edition of WHO Gastrointestinal Tumor Pathology and Genetics. Reference ranges of blood levels of aminotransferases were established by the Health Industry Standard of the People's Republic of China.

\subsection{Statistical analyses}

Statistical analysis was performed using SPSS software package (version 23.0). Spearman grade analysis was used for correlation analyses between pathological data, $\mathrm{IHC}$ results and serum levels of aminotransferases. Single-factor and multifactor Cox regression risk models were used to analyze factors related to postoperative survival in patients with HCC. Kaplan-Meier analysis was used for survival curves affected by serum levels of ALT, AST, GGT and ALP. ROC (receiver operating characteristics) curve analysis generates AUC (area under the curve) which is a quantified measurement predicting 
the effects of clinical characteristics, aminotransferases (ALT, AST, GGT and ALP) and expression/activation of IL-6, IL-17 and p-Stat3 on patients' survival. $p<0.05$ indicates a statistically significant difference between comparisons.

\section{Results}

\subsection{Clinical cancer staging and serum levels of aminotransferases}

Of 98 cases of liver cancer, 70 cases (71.4\%) were defined as clinical cancer stage I, 22 cases (22.40\%) as stage II, 4 cases $(4.10 \%)$ as stage III, and 2 cases (2.00\%) as stage IV, respectively. ROC analysis was used to calculate cut-off values for 4 aminotransferases: AST (men: 36.55U/L, women: 34.50U/L); ALT (men: 46.50U/L, women: 23.65U/L); GGT (men: 81.00U/L, women. $59.50 \mathrm{U} / \mathrm{L}$ ); ALP (men: $102.50 \mathrm{U} / \mathrm{L}$, women: $82.50 \mathrm{U} / \mathrm{L}$ ) ( Table 1). 
Table 1

Clinical demographic data of preoperative and postoperative indicators of HCC patients

\begin{tabular}{|c|c|c|c|c|c|}
\hline \multirow[t]{2}{*}{ Indicators (n) } & \multicolumn{2}{|c|}{ HCC patients } & \multirow[t]{2}{*}{ Indicators (n) } & \multicolumn{2}{|c|}{ HCC patients } \\
\hline & $\mathbf{n}$ & $\%$ & & $\mathbf{n}$ & $\%$ \\
\hline Gender (98) & & & $\operatorname{ALT}(\mathrm{U} / \mathrm{L})(98)$ & & \\
\hline male & 74 & 75.5 & range & 9.5 & 65.00 \\
\hline female & 24 & 24.5 & Mean \pm SD & 39. & 39.58 \\
\hline Age (years) (98) & & & Cut-off value & 46. & $r 23.65$ \\
\hline range & \multicolumn{2}{|c|}{$32-79$} & $\leq 46.5$ or 23.65 & 68 & 69.4 \\
\hline Mean \pm SD & \multicolumn{2}{|c|}{$56.68 \pm 9.74$} & $>46.5$ or 23.65 & 30 & 30.6 \\
\hline Clinical stages (98) & & & AST (U/L) (98) & & \\
\hline I & 70 & 71.4 & range & \multicolumn{2}{|c|}{$0.65-260$} \\
\hline II & 22 & 22.4 & Mean \pm SD & \multicolumn{2}{|c|}{$39.7 \pm 32.60$} \\
\hline III & 4 & 4.1 & Cut-off value & \multicolumn{2}{|c|}{36.50 or 34.50} \\
\hline IV & 2 & 2 & $\leq 36.5$ or 34.5 & 60 & 61.2 \\
\hline Differentiation grade (98) & & & $>36.5$ or 34.5 & 38 & 38.8 \\
\hline high & 11 & 11.2 & GGT (U/L) (98) & & \\
\hline moderate & 54 & 55.1 & range & \multicolumn{2}{|c|}{$4.00-392.00$} \\
\hline low & 33 & 33.7 & Mean \pm SD & \multicolumn{2}{|c|}{$87.17 \pm 73.73$} \\
\hline Follow-up (months) (98) & & & Cut-off value & \multicolumn{2}{|c|}{$\leq 81.00$ or 59.50} \\
\hline range & \multicolumn{2}{|c|}{$1-99$} & $\leq 81$ or 59.5 & 73 & 74.5 \\
\hline Mean \pm SD & \multicolumn{2}{|c|}{$46.69 \pm 25.59$} & $>81$ or 59.5 & 25 & 25.5 \\
\hline BMI (kg/m2) (82) & & & IL-6 (Cancer) (88) & & \\
\hline range & \multicolumn{2}{|c|}{$19.10-34.94$} & $-/+$ & 62 & 70.5 \\
\hline Mean \pm SD & \multicolumn{2}{|c|}{$24.93 \pm 3.15$} & $2+$ & 18 & 20.5 \\
\hline $18.6-23.9$ & 34 & 41.5 & $3+\square 4+$ & 8 & 10 \\
\hline $24-27.9$ & 34 & 41.5 & IL-17 (Cancer) (90) & & \\
\hline$\geq 28$ & 14 & 17 & $-/+$ & 52 & 53.1 \\
\hline $\operatorname{ALP}(U / L)(98)$ & & & $2+$ & 35 & 35.7 \\
\hline range & \multicolumn{2}{|c|}{$21.00-221.00$} & $3+\llbracket 4+$ & 3 & 3.1 \\
\hline Mean \pm SD & \multicolumn{2}{|c|}{$87.17 \pm 31.70$} & p-Stat3 (Cancer) (90) & & \\
\hline Cut-off value & \multicolumn{2}{|c|}{102.50 or 82.50} & $-/+$ & 43 & 43.9 \\
\hline$\leq 102.5$ or 82.5 & 68 & 69.4 & $2+$ & 25 & 25.5 \\
\hline$>102.5$ or 82.5 & 30 & 30.6 & $3+\llbracket 4+$ & 22 & 24.4 \\
\hline
\end{tabular}




\subsection{Expression of IL- 6 and IL-17 and activation of p-Stat3 in liver cancer tissues}

As shown in Figure.1, when IL-6 and IL-17 were expressed, the cytoplasma of HCC and paracancerous cells was stained (from light yellow to brown). Phosphorylated Stat3 ( $p$-Stat3) is the active form of Stat3 which enters the nuclei and, therefore, IHC showed positive staining in the nuclei of carcinoma cells and paracancerous cells (from light yellow to brownish yellow). As shown in Table 2, the positive and strongly positive rates of IL-6 and IL-17 expression in paracancerous tissues were higher than those in HCC tissues. On the other hand, the positive and strongly positive rates of activated p-Stat3 in HCC tissues were higher than those in paracancerous tissues.

Table 2

Comparisons of IHC-based indicators of IL-6, IL-17 and p-Stat3 between cancer and paracancerous tissues

\begin{tabular}{|c|c|c|c|c|c|c|c|c|}
\hline Grouping & $\mathrm{n}$ & - & $1+$ & $2+$ & $3+$ & $\begin{array}{l}\text { Positive } \\
\text { rate }\end{array}$ & $\begin{array}{l}\text { Strong positive } \\
\text { rate }\end{array}$ & $\begin{array}{l}P \\
\text { values }\end{array}$ \\
\hline \multicolumn{9}{|l|}{ IL-6 } \\
\hline $\begin{array}{l}\text { liver } \\
\text { cancer }\end{array}$ & 88 & $\begin{array}{l}12 \\
(13.6 \%)\end{array}$ & $\begin{array}{l}50 \\
(56.8 \%)\end{array}$ & $\begin{array}{l}18 \\
(20.5 \%)\end{array}$ & $8(9.1 \%)$ & $86.30 \%$ & $18.09 \%$ & \multirow[t]{2}{*}{$<0.001$} \\
\hline paracancer & 79 & $2(2.5 \%)$ & $\begin{array}{l}12 \\
(15.2 \%)\end{array}$ & $\begin{array}{l}60 \\
(75.9 \%)\end{array}$ & 5 (6.3\%) & $97.47 \%$ & $60.06 \%$ & \\
\hline \multicolumn{9}{|l|}{ IL-17 } \\
\hline $\begin{array}{l}\text { liver } \\
\text { cancer }\end{array}$ & 90 & $5(5.6 \%)$ & $\begin{array}{l}47 \\
(52.2 \%)\end{array}$ & $\begin{array}{l}35 \\
(38.9 \%)\end{array}$ & 3 (3.3\%) & $94.40 \%$ & $42.40 \%$ & \multirow[t]{2}{*}{$<0.001$} \\
\hline paracancer & 82 & $0(0 \%)$ & $\begin{array}{l}10 \\
(12.2 \%)\end{array}$ & $\begin{array}{l}47 \\
(57.3 \%)\end{array}$ & $\begin{array}{l}25 \\
(30.5 \%)\end{array}$ & $100 \%$ & $87.80 \%$ & \\
\hline \multicolumn{9}{|l|}{ p-Stat3 } \\
\hline $\begin{array}{l}\text { liver } \\
\text { cancer }\end{array}$ & 90 & $\begin{array}{l}23 \\
(25.6 \%)\end{array}$ & $\begin{array}{l}20 \\
(22.2 \%)\end{array}$ & $\begin{array}{l}25 \\
(27.8 \%)\end{array}$ & $\begin{array}{l}22 \\
(24.4 \%)\end{array}$ & $74.44 \%$ & $52.20 \%$ & \multirow[t]{2}{*}{0.010} \\
\hline paracancer & 90 & $\begin{array}{l}22 \\
(24.4 \%)\end{array}$ & $\begin{array}{l}46 \\
(51.1 \%)\end{array}$ & $\begin{array}{l}18 \\
(20.0 \%)\end{array}$ & $4(4.5 \%)$ & $75.50 \%$ & $18.04 \%$ & \\
\hline
\end{tabular}

\subsection{Correlations between various bio-indicators in liver cancer tissues}

As shown in Table 3, there was positive correlations between ALT, AST and GGT $(p<0.01)$, and between ALP and GGT ( $<<$ 0.05). There was a negative correlation between the cell differentiation of hepatocellular cancer cells and the expression of IL6 or IL-17 ( $p<0.01)$, i.e., the more poorly differentiated HCC cells were, the lower the levels of IL- 6 and IL-17 expressed. There was also a positive correlation between IL-6 or IL-17 and p-Stat3 $(p<0.05)$. 
Table 3

Cross correlation analyses of various indices in HCC patients

\begin{tabular}{|c|c|c|c|c|c|c|c|c|c|c|c|}
\hline \multirow[t]{2}{*}{ Index } & \multicolumn{4}{|c|}{ Clinical index } & \multicolumn{4}{|c|}{ aminotransferase } & \multicolumn{3}{|c|}{ Immunohistochemistry } \\
\hline & Gender & Age & $\begin{array}{l}\text { Cell } \\
\text { differ. }\end{array}$ & $\begin{array}{l}\text { TNM } \\
\text { stage }\end{array}$ & ALT & AST & GGT & ALP & IL-6 & IL-17 & $\begin{array}{l}\text { p- } \\
\text { Stat3 }\end{array}$ \\
\hline Gender & 1 & & & & & & & & & & \\
\hline Age & 0.112 & 1 & & & & & & & & & \\
\hline $\begin{array}{l}\text { Cell } \\
\text { differ. }\end{array}$ & -0.095 & -0.031 & 1 & & & & & & & & \\
\hline $\begin{array}{l}\text { TNM } \\
\text { stage }\end{array}$ & -0.085 & 0.137 & 0.195 & 1 & & & & & & & \\
\hline ALT & $-0.284^{\star \star}$ & -0.113 & 0.171 & 0.136 & 1 & & & & & & \\
\hline AST & -0.134 & -0.009 & -0.113 & 0.013 & $0.261^{\star *}$ & 1 & & & & & \\
\hline GGT & $-0.317 \star \star$ & -0.027 & 0.015 & 0.074 & $0.522^{\star \star}$ & $0.491^{\star *}$ & 1 & & & & \\
\hline ALP & 0.013 & 0.057 & 0.001 & 0.098 & 0.056 & -0.001 & $0.200 *$ & 1 & & & \\
\hline IL-6 & 0.091 & 0.059 & $-0.311 \star \star$ & -0.078 & -0.061 & -0.146 & 0.074 & 0.003 & 1 & & \\
\hline IL-17 & -0.081 & -0.199 & $-0.366^{\star \star}$ & -0.024 & -0.291 ** & 0.150 & -0.063 & 0.141 & $0.212^{\star}$ & 1 & \\
\hline $\begin{array}{l}\text { p- } \\
\text { Stat3 }\end{array}$ & 0.029 & 0.009 & -0.180 & 0.062 & -0.079 & 0.141 & 0.020 & -0.092 & 0.310 ** & $0.264^{*}$ & 1 \\
\hline
\end{tabular}

\subsection{Serum levels of aminotransferases are associated with survival outcomes in patients with liver cancer}

Patients with HCC had a maximum postoperative survival time of 99 months by October 2018 (last follow-up date), with a median survival time of 39.5 months. Survival analyses showed that TNM stages were correlated with survival prognosis among liver cancer patients $(p=0.004)$, validating this patient cohort. In addition as expected, cell differentiation was also correlated with the survival of liver cancer patients, i.e., the poorer the cell differentiation, the worse the patients' survival ( $p=$ 0.023) (see Figure. 2). In terms of aminotransferases, it was obvious that the higher the levels of ALT $(p<0.001)$, AST $(p=$ 0.002), GGT ( $p$ <.001) were, the worse the patients' survivals were observed, respectively. Similarly, the higher the levels of ALP were, the worse the patients' survivals were observed $(p<0.001)$. Therefore, higher levels of ALT, AST, GGT and ALP can predict poorer survival prognoses among liver cancer patients (Figure. 2).

\subsection{Predictive values of aminotransferases for survival in liver cancer patients}

In ROC analysis, area under the curve (AUC) reflects the ability or power in predicting survival. The larger a factor's AUC is, the higher its predictive ability can be. The AUCs of ALT was $0.66(p=0.037)$, GGT was $0.662(p=0.036)$ and ALP was $0.708(p=$ 0.007 ), suggesting ALP had the greatest ability to predict postoperative survival and the quality of life among HCC patients (Figure.3).

\subsection{Analyses of risk factors affecting survival prognosis of liver cancer patients}

COX single factor regression model analysis was performed for clinical data (sex, age, cell differentiation and TNM stages), levels of aminotransferases (ALT, AST, GGT and ALP) and expressed/activated IL-6, IL-17 and p-Stat3 among 98 liver cancer 
patients (Table 4). The results showed that risk factors for poor prognosis in HCC patients included poor cell differentiation, TNM stage III + IV, high levels of ALT, AST, GGT, ALP, and high expression levels of IL-6 and IL-17.

Table 4

Cox regression model analyses of bio-indicators in HCC patients

\begin{tabular}{|c|c|c|c|c|}
\hline \multirow[t]{2}{*}{ Variable } & \multicolumn{2}{|c|}{ COX univariate analysis } & \multicolumn{2}{|c|}{ COX multivariate analysis } \\
\hline & $\mathrm{HR}(95 \% \mathrm{Cl})$ & $P$ values & $\mathrm{HR}(95 \% \mathrm{Cl})$ & $P$ values \\
\hline Gender (male vs. female) & $1.494(0.578,3.862)$ & 0.407 & / & / \\
\hline Age $(<61.5$ years vs. $\geq 61.5$ years & $2.018(0.856,4.758)$ & 0.109 & / & / \\
\hline $\begin{array}{l}\text { Cell differentiation grade } \\
\text { (low vs. high + moderate) }\end{array}$ & $2.605(1.105,6.141)$ & 0.029 & $1.398(0.408,4.783)$ & 0.594 \\
\hline TNM stage $(\mathrm{T} \otimes+\mathrm{T} 4$ vs. $\mathrm{T} 1+\mathrm{T} 2)$ & $4.294(1.434,12.862)$ & 0.009 & $2.67(0.621,11.475)$ & 0.187 \\
\hline ALT (low-level vs. high-level) & $7.15(2.871,17.804)$ & $<0.001$ & $3.214(0.707,14.605)$ & 0.131 \\
\hline AST (low-level vs. high-level) & $3.748(1.505,9.335)$ & 0.005 & $2.327(0.676,8.007)$ & 0.18 \\
\hline GGT (low-level vs. high-level) & $6.094(2.472,15.023)$ & $<0.001$ & $1.121(0.291,4.325)$ & 0.868 \\
\hline ALP (low-level vs. high-level) & $6.063(2.472,15.023)$ & $<0.001$ & $5.817(1.87,18.088)$ & 0.002 \\
\hline IL-6 (2+/3+vs. $-/ 1+)$ & $0.192(0.037,0.996)$ & 0.049 & $0.697(0.302,1.611)$ & 0.399 \\
\hline IL-17 (2+/3 + vs. $-/ 1+)$ & $0.056(0.004,0.837)$ & 0.037 & $0.469(0.206,1.067)$ & 0.071 \\
\hline p-Stat3 $(2+/ 3+$ vs. $-/ 1+)$ & $0.725(0.173,3.043)$ & 0.660 & / & / \\
\hline
\end{tabular}

Multifactorial COX regression model analysis revealed that high levels of ALP were an independent risk factor for postoperative survival in patients with liver cancer (Table 4).

\subsection{The power of combinations of risk factors in predicting patients' survival after surgery}

This study attempted to investigate if combinations of multiple risk factors would be more powerful in predicting postoperative prognosis. As shown in Table 5, AST + ALP combination showed an AUC of $0.787(95 \% \mathrm{Cl}, 0.677-0.897)(p<$ 0.001 ) suggesting a better survival predicting ability than those of AST and ALP alone. The same was even better when 3 bioindicators were combined (ALT + AST + ALP, AUC $=0.820$ [95\% Cl, 0.714-0.926], p < 0.001), compared with ALT, AST, and ALP alone. Among these combinations, we found that the 5 factor combination of ALT + AST + ALP + IL-17 + p-Stat3 had the largest AUC value of $0.826(95 \% \mathrm{Cl}, 0.708-0.945)(\mathrm{p}<0.001)$, suggesting the best predicting ability among all combinations (Table 5). 
Table 5

AUCs (area under the curves) for various bio-indicator combinations in HCC patients

\begin{tabular}{|c|c|c|c|c|c|c|c|c|}
\hline Combination mode & Index & AUC & $\begin{array}{l}\text { Lower } \\
\text { limit }\end{array}$ & $\begin{array}{l}\text { Upper } \\
\text { limit }\end{array}$ & $\begin{array}{l}P \\
\text { value }\end{array}$ & Sensitivity & Specificity & $\begin{array}{l}\text { Youden } \\
\text { index }\end{array}$ \\
\hline \multirow{10}{*}{$\begin{array}{l}\text { Aminotransferases } \\
\text { combinations }\end{array}$} & $\mathrm{ALT}+\mathrm{AST}$ & 0.728 & 0.589 & 0.866 & 0.001 & $57.10 \%$ & $89.60 \%$ & 0.467 \\
\hline & $A L T+G G T$ & 0.747 & 0.617 & 0.877 & 0.001 & $71.40 \%$ & $70.10 \%$ & 0.415 \\
\hline & $A L T+A L P$ & 0.781 & 0.671 & 0.891 & $<.001$ & $85.70 \%$ & $64.90 \%$ & 0.506 \\
\hline & $\mathrm{AST}+\mathrm{GGT}$ & 0.746 & 0.619 & 0.872 & 0.001 & $57.10 \%$ & $83.10 \%$ & 0.402 \\
\hline & $A S T+A L P$ & 0.787 & 0.677 & 0.897 & $<0.001$ & $90.50 \%$ & $51.90 \%$ & 0.424 \\
\hline & GGT + ALP & 0.780 & 0.664 & 0.897 & $<0.001$ & $81.00 \%$ & $67.50 \%$ & 0.485 \\
\hline & $\mathrm{ALT}+\mathrm{AST}+\mathrm{GGT}$ & 0.752 & 0.619 & 0.886 & $<.001$ & $71.40 \%$ & $80.50 \%$ & 0.519 \\
\hline & $A L T+A S T+A L P$ & 0.820 & 0.714 & 0.926 & $<001$ & $85.70 \%$ & $71.40 \%$ & 0.571 \\
\hline & $A L T+G G T+A L P$ & 0.809 & 0.706 & 0.911 & $<001$ & $90.50 \%$ & $59.70 \%$ & 0.502 \\
\hline & $\begin{array}{l}\mathrm{ALT}+\mathrm{AST}+\mathrm{GGT} \\
+\mathrm{ALP}\end{array}$ & 0.825 & 0.720 & 0.931 & $<0.001$ & $90.50 \%$ & $67.50 \%$ & 0.580 \\
\hline \multirow[t]{4}{*}{ IHC combinations } & IL-6 + IL-17 & 0.630 & 0.479 & 0.782 & 0.090 & $61.10 \%$ & $62.30 \%$ & 0.234 \\
\hline & IL-6 + p-Stat3 & 0.612 & 0.468 & 0.756 & 0.074 & $57.90 \%$ & $61.80 \%$ & 0.197 \\
\hline & IL-17 + p-Stat3 & 0.643 & 0.487 & 0.799 & 0.062 & $55.60 \%$ & $48.20 \%$ & 0.238 \\
\hline & $\begin{array}{l}\text { IL-6 + IL-17 + p- } \\
\text { Stat3 }\end{array}$ & 0.646 & 0.485 & 0.808 & 0.057 & $55.60 \%$ & $79.40 \%$ & 0.350 \\
\hline \multirow[t]{7}{*}{$\begin{array}{l}\text { Aminotransferases plus } \\
\text { IHC combinations }\end{array}$} & $\begin{array}{l}\text { ALT + AST + ALP } \\
+I L-6\end{array}$ & 0.819 & 0.713 & 0.924 & $<.001$ & $78.90 \%$ & $78.30 \%$ & 0.572 \\
\hline & $\begin{array}{l}\text { ALT + AST + ALP } \\
+ \text { IL-17 }\end{array}$ & 0.821 & 0.712 & 0.931 & $\begin{array}{l}< \\
0.001\end{array}$ & $77.80 \%$ & $79.20 \%$ & 0.570 \\
\hline & $\begin{array}{l}\text { ALT + AST + ALP } \\
+ \text { p-Stat3 }\end{array}$ & 0.813 & 0.685 & 0.940 & $<.001$ & $78.90 \%$ & $83.10 \%$ & 0.620 \\
\hline & $\begin{array}{l}\text { ALT + AST + ALP } \\
+I L-6+I L-17\end{array}$ & 0.822 & 0.715 & 0.929 & $<001$ & $77.80 \%$ & $81.20 \%$ & 0.590 \\
\hline & $\begin{array}{l}\text { ALT + AST + ALP } \\
+ \text { IL-6 + p-Stat3 }\end{array}$ & 0.821 & 0.704 & 0.938 & $<.001$ & $73.70 \%$ & $88.20 \%$ & 0.619 \\
\hline & $\begin{array}{l}\text { ALT + AST + ALP } \\
+ \text { IL-17+ p-Stat3 }\end{array}$ & 0.826 & 0.708 & 0.945 & $<001$ & $72.20 \%$ & $87.30 \%$ & 0.595 \\
\hline & $\begin{array}{l}\text { ALT + AST + ALP } \\
+ \text { IL-6 + IL-17 + p- } \\
\text { Stat3 }\end{array}$ & 0.817 & 0.698 & 0.936 & $<0.001$ & $72.20 \%$ & $88.20 \%$ & 0.604 \\
\hline \multicolumn{9}{|c|}{ Note: Bold numbers indicate the highest AUC in that category. } \\
\hline 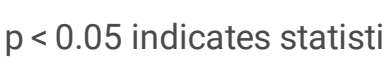 & difference. & & & & & & & \\
\hline
\end{tabular}


Liver diseases are a global healthcare burden with estimated 844 million people worldwide suffering from chronic liver diseases and an annual mortality rate of 2 million. ${ }^{1}$ Two main epithelial cell types in the liver are hepatocytes and biliary cells. Hepatocytes make up the majority of the liver with various functions including protein synthesis, detoxification, bile production, and carbohydrate and lipid metabolism, ${ }^{4}$ so damages to hepatocytes may severely affect liver's functions. HCC causes massive necrosis of the hepatocytes resulting in the loss of their physiological functions. Liver cancer is a very common malignant tumor with a complicated pathogenesis and the survival prognosis and the quality of life are the result of interactions of many factors. Early detection and treatment of liver cancer can significantly improve the survival and quality of life for patients with liver cancer. If managed properly, such as surgical removal and radio-chemotherapy, patients with late stage liver cancer may enjoy a prolonged life time and reasonable quality of life. Therefore, this study has aimed at investigating potential risk factors which affect prognosis before surgery that may provide a comprehensive guidance to clinicians in their making appropriate surgical approaches and postoperative treatment strategies.

Stat3 signaling pathway is a pro-inflammatory pathway that has been shown to be involved in chronic inflammation, autoimmunity, infectious diseases and cancer, and the members of the pathway are often used as diagnostic or prognostic indicators of disease activity and response to therapy. ${ }^{5} \mathrm{IL}-6$ is an upstream molecule capable of activating Stat 3 pathway and $\mathrm{IL}-17$ is a downstream molecule that is expressed in response to the activation of Stat3.

The present study has shown that IL-6 is highly expressed in paracancerous tissues (Table 2). Table 3 shows that the expression of IL- 6 is inversely correlated with the cell differentiation of HCC. A previous study of HCC has shown that HCC tissues expressing lower IL-6 levels are correlated with a better prognosis, longer overall survival, and longer time to recurrence, ${ }^{6}$ somewhat similar to the results in this study.

On the other hand, there is growing evidence that IL-17 has an important contextual and tissue-dependent role in maintaining health in response to injury, physiological stress, and infection. ${ }^{7}$ IL-17 is not only associated with the immunity of the body, but its role in the development of tumors has also become a focus of research. Similar to IL-6, the current study shows that expressed IL-17 is higher in paracancerous tissues than in HCC tissues (Table 2). Again as shown in Table 3, IL-17 expression is inversely associated with the cell differentiation of HCC. Thus far, published reports support a pathogenic role of IL-17 in cancer development including cancers of the colon, ${ }^{8}$ the skin, ${ }^{9}$ the pancrea, ${ }^{10}$ the hepatocytes, ${ }^{11}$ the lung, ${ }^{12}$ and multiple myeloma. ${ }^{13}$ Patients with UCC may experience a poorer survival prognosis and a higher degree of infiltration of lymphocytes if IL-17 is highly expressed. ${ }^{11,14}$

Several reports have suggested that over-activated Stat3 is present in a variety of tumor cells and immune cells, suggesting that over-activated Stat3 may influence the body's ability to generate an effective immune response, thereby participate in tumor formation and promote tumor cell proliferation, migration, differentiation, and metastasis. ${ }^{15,16}$ The present study shows a higher level of activated p-Stat3 in HCC tissues (Table 2) in keeping with the abovementioned reports. In addition, studies have shown that esophageal squamous cell carcinoma and adenocarcinoma have higher IHC scores for p-Stat3 in tumor tissues when cancer cells have higher migration and proliferation. ${ }^{17}$ Furthermore, activated Stat3 can bind to the promoter region of the SKp2 gene which is a proto-oncogene associated with cervical carcinogenesis. ${ }^{18}$ In summary, IL-6/Stat3/IL-17 pathway forms a cascade that has been indicated to play an important role in the development, progression and prognosis of several cancers including HCC. ${ }^{19}$ In this context, the current study warrants further investigations as to the detailed mechanism(s) of the Stat3 pathway in the pathogenesis and prognosis of cancer.

Testing of blood liver enzymes is routinely performed and changes in levels of aminotransferases are important diagnostic indicators revealing detrimental impacts to hepatocytes, therefore, liver functions. For example, elevated levels of ALT and AST may indicate hepatocyte-dominated disease, while elevated levels of ALP and GGT may suggest cholestasis-dominated disease. ${ }^{20}$ The sources of AST can be multiple organs including liver, heart, skeletal muscles, kidneys, brain, or red blood cells. ${ }^{21,22}$ However, ALT are more specifically derived from the liver and therefore is the preferred clinical test for diagnosing liver disease. GGT is a membrane-bound enzyme that is a key enzyme in biotransformation, nucleic acid metabolism, 
catalyzing the degradation of extracellular glutathione (GSH). GSH is critical in protecting cells from oxidant-induced damage produced during normal metabolism. ${ }^{23}$ ALP is a hydrolytic enzyme that is widely present in hepatocytes and blood sinuses of the bile duct membrane and is associated with the uptake and transport of certain substances. Elevated serum levels of ALP are associated with liver diseases including HCC, cholangiocarcinoma, and biliary cirrhosis. ${ }^{24} \mathrm{~A}$ previous case-control study has found that blood levels of GGT, ALT, and AST are elevated in approximately $90 \%$ of cases liver cancer, while half of the cases also show elevated levels of liver-specific ALP or bilirubin. ${ }^{25}$

A retrospective study has investigated the relationship of ALT, AST, GGT and ALP with HCC among patients who underwent hepatectomy and found that ALT, AST, GGT and ALP are positively associated with the risk of HCC and, GGT and AST/ALT are independent risk factors predicting postoperative survival in patients with primary $\mathrm{HCC}^{8}{ }^{8}$ These observations are consistent with our findings presented here. Due to the role of GGT in the degradation of glutathione (GSH), GGT has been associated with oxidative stress which may induce a microenvironment that promotes tumor growth in the liver. ${ }^{26}$ There is also evidence of elevated GGT in patients with obesity or diabetes or hepatic steatosis ${ }^{27}$ which are associated with metabolic syndrome that it is itself associated with an increased risk of HCC. ${ }^{28}$

Having validated the patient cohort using conventional TNM clinical staging to predict survival prognosis among HCC patients, we have analyzed and found that elevated levels of all 4 enzymes are correlated with poor survival among these HCC patients (Figure. 2). To investigate individual ability of these enzymes in survival prediction, we have adopted AUC (area under the curve) for this purpose. AUC reflects the ability in predicting survival by which the larger a factor's AUC is, the higher its predictive ability is. As shown in Figure. 3, among ALT, AST, GGT and ALP enzymes, ALP shows the highest AUC of 0.708, suggesting its greatest ability to predict postoperative survival and the quality of life in patients with HCC. The above conclusion is confirmed by multifactorial COX regression analysis which reveals elevated levels of ALP are an independent risk factor for postoperative survival in HCC patients (Table 4). Quantifying prediction ability for individual enzyme is advantageous because clinicians can judge the reliability of a risk factor used in their survival analyses.

A novel approach in this study is the combinational analysis of multiple bio-factors that can be able to increase AUC values. For example, a 5-factor combination of ALT + AST + ALP + IL-17 + p-Stat3 shows significantly larger AUC value (0.826) than a 2 -factor combination of AST + ALP (AUC $=0.787)$, suggesting a higher predicting power (Table 5). This approach is significant in that clinicians may use multiple routinely tested factors to reliably predict 5-year survival preoperatively before surgery.

In summary, we have shown 3 major findings in this investigation: (1) IL-6/Stat3/IL-17 signaling pathway is involved in survival prognosis among HCC patients; (2) Liver function-related aminotransferases ALT, AST, GGT and ALP can predict survival prognosis for HCC patients before surgery; and (3) A novel approach of combining multiple risk factors can be used to better predict HCC patients' survival prognosis and quantifying prediction power using ROC analysis (AUC values) for individual risk factors may facilitate clinicians to judge the reliability of survival analyses. Utilizing routinely tested clinical bioindicators to predict potential survival prognosis before surgery is significant in terms of facilitating surgeons' decisionmaking for personalized surgical approaches as well as appropriate radio-chemotherapy after surgery. However, to establish a clinically practical protocol, e.g., the cutoff values for serum levels of individual enzymes for survival predictions to be used as clinicians' guiding reference, requires a much larger sample of HCC patients. Our ongoing investigation is aimed at organizing a multi-center collaboration study to accomplish the above goal.

\section{Declarations}

\section{Date sharing statement}

All the data generated or analyzed during this study are included in this article.

\section{Acknowledgements}


We sincerely thank all patients participated in this investigation. We are grateful to the Ministry of Science and Technology of China, the Bureau of Science and Technology of the Xinjiang Corps, and Shihezi University for their generous financial support.

\section{Funding}

This work was supported by grants from the Ministry of Science and Technology of China (No. 2009BAI82B02) and the Oasis Scholar Fund of Shihezi University (No. LZXZ201023). The funder had no role in study design, data collection and analysis, decision to publish or preparation of the manuscript.

\section{Author's contributions}

Planning and execution of the study: LJW, XNL, LT and WJZ. Manuscript drafting: LJW, XNL, LT. Manuscript revision: WJZ. All authors approve the final draft and agree to be accountable for all aspects of the works.

\section{Ethics approval and consent to participate}

Ethical approval was obtained from the Institutional Ethics Review Board (IERB) of the First Affiliated Hospital of School of Medicine, Shihezi University (No. 2018-067-01). The IERB waived the need for patient consents due to anonymous analyses of the data and confidentiality and anonymity in the handling and publication of patients' tissues. Standard University Hospital

Guidelines in accordance with the Declaration of Helsinki were followed in this study.

\section{Patient consent for publication}

Not applicable.

\section{Competing interests}

The authors declare that they have no competing interests.

\section{References}

1. Bray F, Ferlay J, Soerjomataram I, et al. Global cancer statistics 2018: GLOBOCAN estimates of incidence and mortality worldwide for 36 cancers in 185 countries. CA cancer J Clin. 2018;68:394-424. doi:10.3322/ caac.21492

2. Menghini G. One-second needle biopsy of the liver. Gastroenterology, 1958, 35: 190-9.

3. Li YX, Zhang L, Simayi D, et al. Human Papillomavirus Infection Correlates with Inflammatory Stat3 Signaling Activity and IL-17 Level in Patients with Colorectal Cancer. Plos One, 2015, 10(2):e0118391. doi: 10.1371/journal.pone.0118391. eCollection 2015.

4. Ramachandran P, Matchett KP, Dobie R, et al. Single-cell technologies in hepatology: new insights into liver biology and disease pathogenesis. Nature reviews Gastroenterology \& hepatology, 2020,08;178.doi: 10.1038/s41575-020-0304-x

5. Kishimoto T. IL-6: from its discovery to clinical applications. International immunology, 2010,22: 347-52. doi:10.1093/intimm/dxq030

6. Yang X, Liang L, Zhang XF, et al. MicroRNA-26a suppresses tumor growth and metastasis of human HCC by targeting interleukin-6-Stat3 pathway. Hepatology, 2013,58:158-70. doi:10.1002/ hep.26305

7. Mcgeachy MJ, Cua DJ, Gaffen SL. The IL-17 Family of Cytokines in Health and Disease. Immunity, 2019, 50: 892906.doi:10.1016/j.immuni.2019.03.021

8. Zepp Ja, Zhao J, Liu C, et al. IL-17A-Induced PLET1 Expression Contributes to Tissue Repair and Colon Tumorigenesis. Journal of immunology , 2017, 199: 3849-57. doi:10.4049/jimmunol.1601540

9. Wang L, Yi T, Zhang W, et al. IL-17 enhances tumor development in carcinogen-induced skin cancer. Cancer research, 2010,70:10112-20. doi:10.1158/0008-5472.CAN-10-0775

Page $12 / 16$ 
10. Zhang Y, Zoltan M, Riquelme E, et al. Immune Cell Production of Interleukin 17 Induces Stem Cell Features of Pancreatic Intraepithelial Neoplasia Cells. Gastroenterology, 2018,155:210-23.e3. doi:1105 3/j.gastro.2018.03.041.

11. Sun C, Kono H, Furuya S, et al. Interleukin-17A Plays a Pivotal Role in Chemically Induced HCC in Mice. Digestive Diseases \& Sciences, 2016,61:474-88. doi:10.1007/ s10620-015-3888-1

12. Jin C, Lagoudas Gk, Zhao C, et al. Commensal Microbiota Promote Lung Cancer Development via y反 T Cells. Cell, 2019, 176: 998-1013.e16. doi:10.1016/j.cell.2018.12.040

13. Calcinotto A, Brevi A, Chesi M, et al. Microbiota-driven interleukin-17-producing cells and eosinophils synergize to accelerate multiple myeloma Nature communications, 2018,9:4832. doi:10.1038/s41467-018-07305-8

14. Hu Z, Luo D, Wang D, et al. IL-17 Activates the IL-6/Stat3 Signal Pathway in the Proliferation of Hepatitis B Virus-Related HCC. Cellular physiology and biochemistry, 2017,43:2379-90. doi:10.1159/00 0484390

15. Yu H, Lee H, Herrmann A, et al. Revisiting Stat3 signalling in cancer: new and unexpected biological functions. Nature reviews Cancer, 2014, 14:736-46. doi:10.1038/nrc3818

16. Yu H, Pardoll D, Jove R. STATs in cancer inflammation and immunity: a leading role for Stat3. Nature reviews Cancer, 2009, 9:798-809. doi:10.1038/nrc2734

17. Miao FC, Ping-Tsung Chen, et al. IL-6 expression predicts treatment response and outcome in squamous cell carcinoma of the esophagus. Molecular Cancer, 2013,12:26. doi:10.1186/1476-459 8-12-26

18. Huang H, Zhao W, Yang D. Stat3 induces oncogenic Skp2 expression in human cervical carcinoma cells. BBRC, 2012, 418: 186-90.doi:10.1016/j.bbrc.2012.01.004

19. Wang L, Yi T, Kortylewski M, et al. IL-17 can promote tumor growth through an IL-6-Stat3 signaling pathway. The Journal of experimental medicine, 2009, 206:1457-64. doi:10.1084/jem.20090207

20. Giannini EG, Testa R, Savarino V. Liver enzyme alteration: a guide for clinicians. CMAJ: Canadian Medical Association journal, 2005,172: 367-79. doi:10.1503/cmaj.1040752

21. Dufour DR, Lott JA, Nolte FS, et al.Diagnosis and monitoring of hepatic injury. II. Recommendations for use of laboratory tests in screening, diagnosis, and monitoring. Clinical chemistry, 2000, 46:2050-68.

22. Zhang LX, Lv Y, Xu AM, et al. The prognostic significance of serum gamma-glutamyltransferase levels and AST/ALT in primary hepatic carcinoma. BMC cancer, 2019,19: 841. doi:10.1186./s12885-019-6011-8

23. Whitfield JB. Gamma glutamyl transferase. Critical reviews in clinical laboratory sciences, 2001,38: 263-355. doi:10.1080/20014091084227

24. Cai X, Chen Z, Chen J, et al. Albumin-to-Alkaline Phosphatase Ratio as an Independent Prognostic Factor for Overall Survival of Advanced HCC Patients without Receiving Standard Anti-Cancer Therapies. Journal of Cancer, 2018,9:189-97. doi:10.7150/jca.21799

25. Yang JG, He XF, Huang B, et al. Rule of changes in serum GGT levels and GGT/ALT and AST/ALT ratios in primary hepatic carcinoma patients with different AFP levels. Cancer biomarkers, 2018,21:743-6. doi:10.3233/CBM-170088

26. Zhao J, Zhao Y, Wang H, et al. Association between metabolic abnormalities and HBV related hepatocelluar carcinoma in Chinese: a cross-sectional study. Nutrition journal, 2011,10:49. doi:10.1186/1475-2891-10-49

27. Jiang S, Jiang D, Tao Y. Role of gamma-glutamyltransferase in cardiovascular diseases. Experimental and clinical cardiology, 2013,18: 53-6.

28. Jinjuvadia R, Patel S, Liangpunsakul S. The association between metabolic syndrome and HCC: systemic review and meta-analysis. Journal of clinical gastroenterology, 2014,48:172-7. doi:10.1097/MCG.0b013e31

\section{Figures}


Fig.1

IL-6
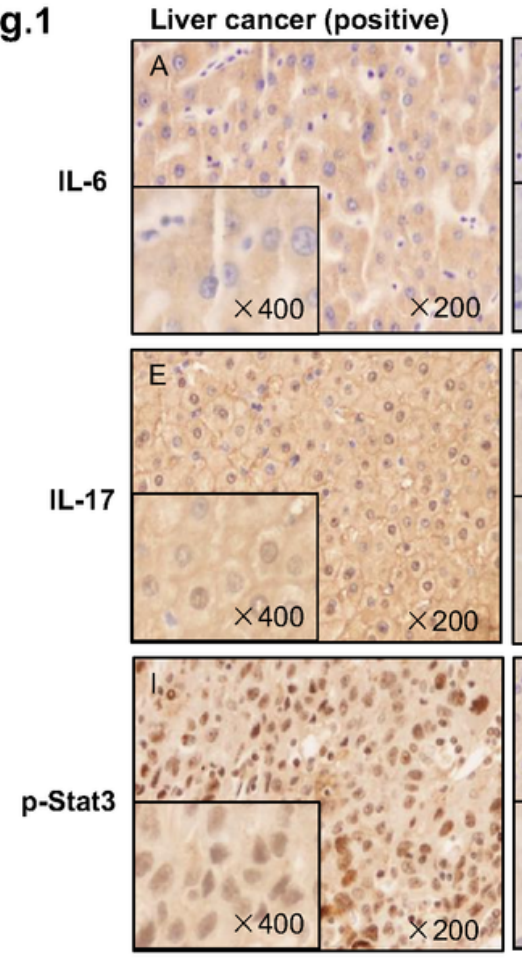

Paracancer (negative)
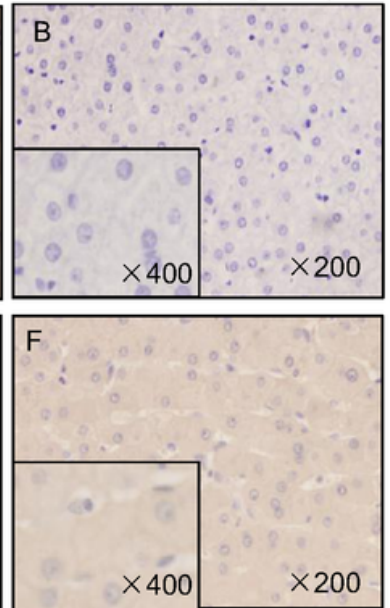

Liver cancer (positive)
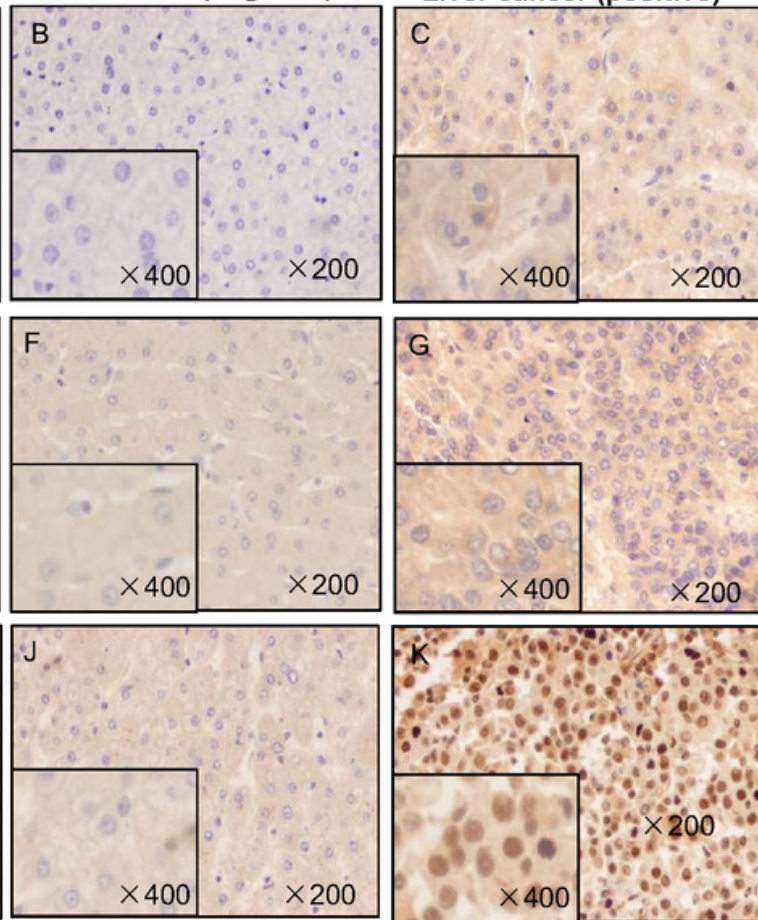

Paracancer (negative)
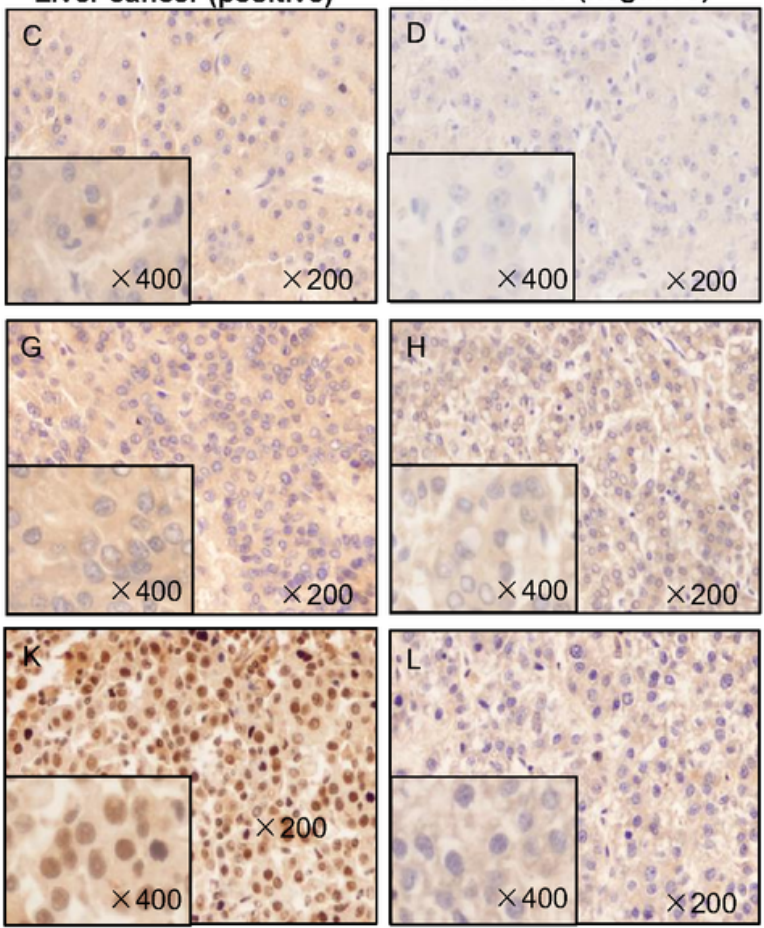

\section{Figure 1}

Immunochemistry (IHC) detection of expressed IL-6 and IL-17, and activated Stat3 (phosphorylated Stat3 or p-Stat3) in HCC tissues and paracancerous tissues. Panels A, E and I are positive IHC staining of IL-6, IL-17 and p-Stat3, respectively in paracancerous tissues (magnification $\times 200$ ). Panels B, F and $\mathrm{J}$ are negative staining IL-6, IL-17 and p-Stat3, respectively in paracancerous tissues (magnification $\times 200$ ). Panels $\mathrm{C}, \mathrm{G}$ and $\mathrm{K}$ are positive staining of IL-6, IL-17 and p-Stat3, respectively in HCC tissues (magnification $\times 200$ ). Panels D, $\mathrm{H}$ and L are positive staining of IL-6, IL-17 and p-Stat3, respectively in HCC tissues (magnification $\times 200$ ). Insert image in each panel is an enlargement at magnification $\times 400$. 
Fig. 2
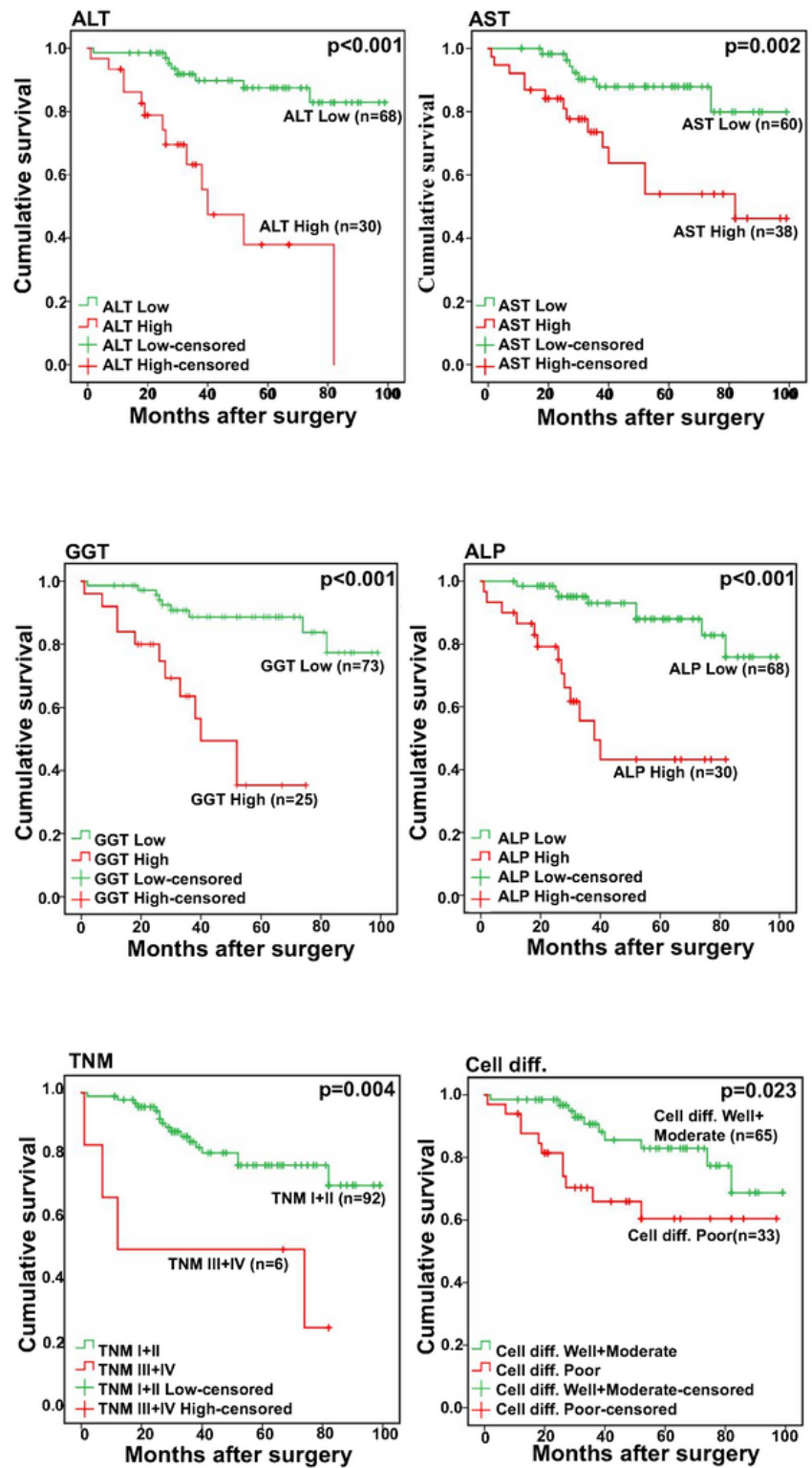

Figure 2

Impacts of TNM staging, cell differentiation, ALT, AST, GGT and ALP on the survival of HCC patients. Comparisons of KaplanMeier survival curves for HCC patients categorized as the following: high vs. low serum levels of ALT $(p<0.01), A S T(p=0.02)$, GGT $(p<0.01)$ and ALP $(p<0.01)$, respectively; clinical staging of TNM I+II vs. TNM III+IV ( $p=0.04)$; cell differentiations of well+moderate vs. poor $(p=0.023)$. 
Fig. 3

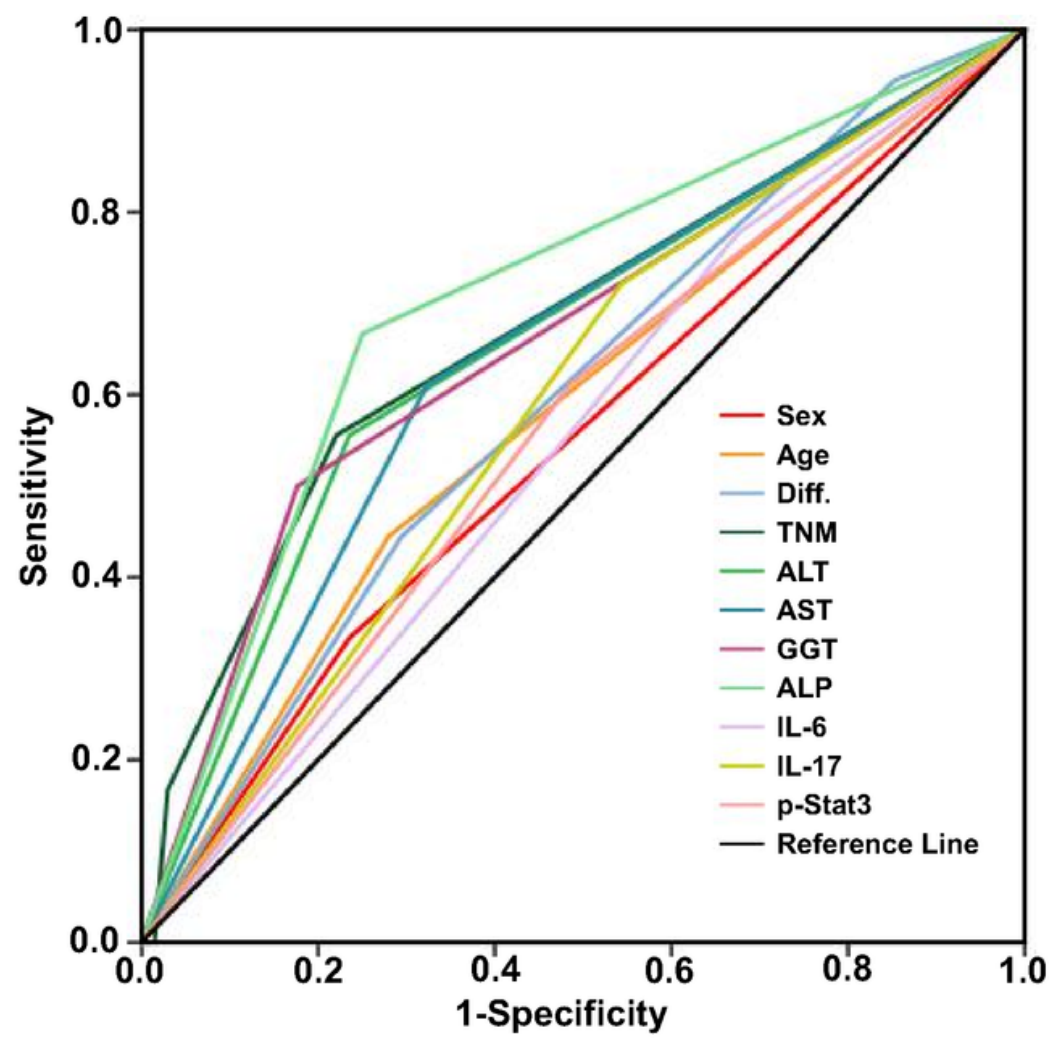

\section{Figure 3}

ROC curves reveal performance abilities of clinicopathological indices, IHC bio-indicators, and their combinations affecting patients' survival. As shown, the diagonal black line is the reference line.

\section{Supplementary Files}

This is a list of supplementary files associated with this preprint. Click to download.

- 4.Supplementarytable.docx 